\title{
Safety Evaluations of Topical Vitamin K1 for Epidermal Growth Factor Receptor Inhibitor-Induced Rash
}

\author{
Julie Ryan Wolf ${ }^{1 *}$, Ramina Nabiee ${ }^{2}$, Braden Candela ${ }^{3}$, Shadi Nassirirad ${ }^{2}$, Reza Mehvar ${ }^{2}$, Hamidreza Montazeri Aliabadi², and Siu \\ Fun Wong ${ }^{2}$
}

${ }^{1}$ Dermatology, University of Rochester Medical Center, Rochester, NY, USA

${ }^{2}$ Chapman University School of Pharmacy, Irvine, CA, USA

${ }^{3}$ University of Rochester School of Medicine \& Dentistry, Rochester, NY, USA

*Corresponding author: Julie Ryan Wolf, PhD, MPH, Department of Dermatology, University of Rochester Medical Center, 601 Elmwood Ave, Box 697, Rochester, NY 14642, USA, Tel: (585) 276-3862; E-mail: Julie_Ryan@urmc.rochester.edu

Received: 02 Dec, 2020 | Accepted: 28 Dec, 2020 | Published: 06 Jan, 2021

Citation: Wolf JR, Nabiee R, Candela B, Nassirirad S, Mehvar R, et al. (2020) Safety Evaluations of TopicalVitamin K1 for Epidermal Growth Factor Receptor Inhibitor-Induced Rash. J Drug Res Dev 7(1): dx.doi.org/10.16966/2470-1009.158

Copyright: (C) 2020 Wolf JR, et al. This is an open-access article distributed under the terms of the Creative Commons Attribution License, which permits unrestricted use, distribution, and reproduction in any medium, provided the original author and source are credited.

\begin{abstract}
Papulopustular rash occurs in $80 \%$ of patients receiving Epidermal Growth Factor Receptor Inhibitor therapy for cancer. Topical vitamin K1, a phosphatase inhibitor, could reduce epidermal growth factor receptor inhibitor-induced rash. This preliminary safety study evaluated a novel topical $0.1 \%$ vitamin K1product for potential use in patients with epidermal growth factor receptor inhibitor-induced rash. Ten healthy subjects applied topical $0.1 \%$ vitamin $\mathrm{K} 1$ to healthy and tape stripped skin every 12 hours for five doses. Vitamin K1 levels were measured by ELISA in serum and plasma at 0,26 , and 50 hours. Vitamin K1 levels ranged between 0 to $8.22 \mathrm{ng} / \mathrm{ml}$. Bivariate correlative analyses showed no association between mean vitamin $\mathrm{K} 1$ concentration and time $(r=0.008, p=0.930)$. Using a range of vitamin $\mathrm{K} 1$ concentrations ( 2.5 to $100 \mathrm{ng} / \mathrm{ml})$ that encompassed and exceeded the levels detected in our healthy subjects, we evaluated the ability of vitamin K1 to reverse cetixumab-induced Epidermal Growth Factor Receptor inhibition in A549 lung cancer cells. Vitamin K1 did not significantly change phosphorylated-Epidermal Growth Factor Receptor levels in cetuximab-treated cells ( $p>0.670$ ). In conclusion, systemic vitamin $\mathrm{K} 1$ levels up to $100 \mathrm{ng} / \mathrm{ml}$ would not interfere with epidermal growth factor receptor inhibitor therapy. Our next step is to test the effectiveness of our 0.1\% topical VK1 formulation for Epidermal Growth Factor Receptor Inhibitor-induced rash in patients receiving epidermal growth factor receptor inhibitor therapy in a randomized, placebo-controlled, blinded study.
\end{abstract}

Keywords: Epidermal Growth Factor Receptor Inhibitor; Rash; Vitamin K1; Topical

\section{Introduction}

Epidermal Growth Factor Receptor Inhibitor (EGFRI) therapy is a common and successful cancer treatment, often combined with chemotherapy [1]. Patients receiving these treatments commonly experience skin rash, pruritus, tenderness and inflammation of hair follicles (folliculitis), along with diarrhea and other symptoms [2]. A characteristic papulopustular rash occurs in $75-90 \%$ of patients receiving EGFRI therapy (eg, cetuximab and erlotinib) [3], is often dose-dependent, and usually presents during the first 2 weeks of therapy [3-5]. The discomfort and physical appearance of the rash can affect patients' quality of life and adherence to treatment [3-6]. Interests in this papulopustular rash have increased over time due to its possible relationship with treatment response and patient survival. These data were first reported by Cunningham $\mathrm{D}$, et al. [7] followed by a meta-analysis conducted by Perez-Soler R, et al. [8,9], who concluded that rash can be a surrogate marker of effective inhibition and activity of EGFR-targeted agents. Several publications have further supported these meta-analysis results [3,10-14]. Therefore, the need to manage EGFRI-induced skin rash in a more optimal manner is warranted.
The current management approach of the EGFRI-induced rash is primarily symptomatic control [3,10-12,15-17]. The need for treatments to relieve the physical and emotional discomfort, particularly in patients with advanced-stage cancer and poor prognosis, is substantial [16]. Investigators have assessed a number of therapeutic interventions for managing the EGFRI-induced rash, including oral and topical antibiotics, topical or systemic corticosteroids, topical retinoids, antihistamines, and pregabalin [3,9,14,17-19]. However, minimal success of these therapeutics suggests a different underlying mechanism for EGFRI rash compared to acne or allergic reactions. Scientific evidence supports a central role of EGFR signalling in keratinocytes to maintain skin homeostasis and other potential underlying mechanisms of EGFRI-induced rash [20].

Vitamin $\mathrm{K}$, a fat-soluble vitamin consisting of phytomenadione $(\mathrm{K} 1)$, menaquinones (K2), and menadione (K3), is involved in the clotting cascade and shown to activate EGFR by inhibition of EGFRrelated phosphatase. Vitamin K1 (VK1) is a naturally occurring analog of the synthetic vitamin K3. A dose-finding studies by Hana 
Biosciences found $0.1 \%$ menadione topical lotion to be most tolerable compared to $0.2 \%$ and $0.05 \%$ [21]. Clinical trials conducted with $0.1 \%$ VK1 topical treatment for EGFRI-induced rash had positive outcomes for both prophylactic and treatment indications. In the prophylactic setting, $0.1 \%$ VK1 cream reduced the intensity and frequency of cetuximab-induced cutaneous toxicity in cancer patients in two of three research studies [16,22-24]. In the treatment setting, improvements of cutaneous toxicity were reported by both research groups in Slovenia and Italy $[15,17]$. Since the topical VK1 cream used in the previously published studies is not available in the United States, our team formulated a topical $0.1 \%$ VK1 product that demonstrated minimal permeability using an ex vivo porcine skin model [25]. In the current investigation, we conducted an in vivo pharmacokinetic study in healthy human subjects using this topical formulation to evaluate systemic penetration of VK1 and tolerability of the product. To further substantiate the safety of the product, we explored the potential for these systemic VK1 levels to reverse cetuximab-induced EGFR inhibition in lung cancer cells.

\section{Materials and Methods}

\section{Study population and design}

The two-phase, pharmacokinetic pilot study was approved by Chapman University Institutional Review Board and University of Rochester Research Subjects Review Board. All subjects provided informed consent. We evaluated the systemic absorption of VK1 from topical application of a $0.1 \%$ VK1 product in 10 healthy subjects. Since skin inflammation can alter the absorption rate of substances applied to the skin, we evaluated the extent of systemic absorption of the topical VK1 product in healthy skin and inflamed skin. In Phase 1, subjects applied the product to skin on the inner side of the forearm every 12 hours for five applications (Figure 1). The fingertip unit technique was used to standardize the application of the topical product. Blood samples (i.e., serum and plasma) were collected at three time points: 1) baseline (before the initiation of VK1 application); 2) two hours after third application (i.e., 26 hours); and 3) two hours after fifth application (i.e., 50 hours). Two weeks later, in Phase 2, skin inflammation was induced in the opposite forearm using the tape stripping method $[26,27]$. Briefly, tape stripping was performed ten times on an $8 \times 4 \mathrm{~cm}^{2}$ area (i.e., $~ 2 \%$ BSA) using scotch tape (Scotch Magic Tape 810, 3M Company, St Paul, MN) [27-29]. Subjects applied the $0.1 \% \mathrm{VK} 1$ product to the tape stripped skin on the inner forearm every 12 hours for five applications in the same manner as Phase 1. Blood samples were collected as described in Phase 1. At each blood collections, serum was collected in $5 \mathrm{ml}$ SST tubes and plasma in $5 \mathrm{ml}$

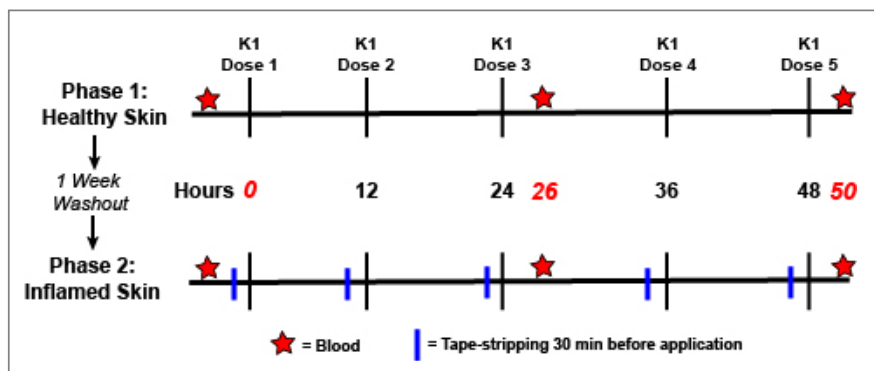

Figure 1: Pharmacokinetic pilot study design.

This diagram illustrates the timing of VK1 applications and blood collections in healthy skin (Phase 1) and tape stripped skin (Phase 2). Short vertical lines represent tape stripping 30 minutes before topical VK1 application. Stars represent blood collection.
K2-EDTA tubes. For serum, blood clotted for 30 minutes to two hours at room temperature or overnight at $4^{\circ} \mathrm{C}$. Serum and plasma were separated by centrifugation, aliquoted, and frozen at $-80^{\circ} \mathrm{C}$.

\section{Topical 0.1\% VK1 product}

Topical $0.1 \%$ VK1 was prepared as previously described [25]. Briefly, the topical product was a water in oil lotion (Formulation L.W/O23), consisting of surfactant system sorbitan monooleate/ polyoxyethylene 23 lauryl ether and $74 \%$ lipid content (sesame oil, white petrolatum, cetaryl alcohol, and isopropyl myristate). Synthetic VK1 (phytonadione; Skin Actives Scientific, Gilbert, AZ) was compounded to the strength of $0.1 \%$ in the above lotion. Among the library of formulations studied, the selected formulation had a viscosity of $357 \pm 17$ and the lowest in vitro transdermal absorption rate at 12 hours (1.75\%) and 24 hours (10.97\%) [25]. Our topical formulation indicated reasonable stability at ambient temperatures showing $98.1 \% \mathrm{VK} 1$ in the topical product after four months of storage away from light.

\section{VK1 ELISA assay}

VK1 concentrations were measured in plasma and serum samples using Human VK1 ELISA (MBS267859, MyBioSource.com, San Diego, CA) following the manufacturer's protocol. The detection range of this ELISA kit was $0.156 \mathrm{ng} / \mathrm{ml}$ to $10 \mathrm{ng} / \mathrm{ml}$ with sensitivity (minimum detectable concentration) of $0.05 \mathrm{ng} / \mathrm{ml}$. The intra- and inter-assay precisions are $\leq 8 \%$ and $\leq 12 \%$, respectively. Samples were run without dilution in duplicate for two separate runs (i.e., each sample measured four times). Absorbance was read at $450 \mathrm{~nm}$. All standard curve coefficients of determinations $\left(r^{2}\right)$ were $\geq 0.99$ for valid and reliable VK1 concentration calculations for serum and plasma samples. Negative values, representing undetectable VK1 levels by the ELISA kit, were designated "0" for analyses.

\section{In vitro experiments with A549 lung cancer cells}

In vitro experiments were performed to determine the effect of several doses of VK1 on EGFR activation following cetuximab treatment in A549 lung cancer cells (Figure 2).

Step 1: A549 cells (courtesy of Dr. Jacob Finkelstein at University of Rochester Medical Center) were cultured in RPMI media containing $10 \%$ heat-inactivated fetal bovine serum (FBS) and penicillin/ streptomycin/glutamine at $37^{\circ} \mathrm{C}(5 \% \mathrm{CO} 2)$. Cells were plated at $2 \times$ 105 cells/well in 12-well plates and grown overnight.

Step 2: Cells were starved in $1 \%$ media overnight at $37^{\circ} \mathrm{C}$ followed by various treatment regimens using cetuximab, VK1, and EGF in $300 \mu \mathrm{l}$ of $1 \%$ media.

Step 2.1: Cetuximab treatment: Cells were treated with 55 or $160 \mu \mathrm{g} / \mathrm{ml}$ of cetuximab $(2 \mathrm{mg} / \mathrm{ml}$, provided by the Investigational Drug Pharmacy at University of Rochester Medical Center) in $1 \%$ media to simulate standard treatment plasma concentrations because the peak plasma levels from standard cetuximab cancer treatment of $100 \mathrm{mg} /$ $\mathrm{m}^{2}$ and $250 \mathrm{mg} / \mathrm{m}^{2}$ were $54.7 \mu \mathrm{g} / \mathrm{ml}$ and $158.1 \mu \mathrm{g} / \mathrm{ml}$, respectively [30].

Step 2.2: VK1 treatment: VK1 dosing of 2.5,5,10,25,50,75, or $100 \mathrm{ng} / \mathrm{ml}$ included the highest concentration detected in the blood after topical $0.1 \%$ VK1 application (i.e., $8 \mathrm{ng} / \mathrm{ml}$ ). Chapman University supplied the same Human VK1 $(2 \mathrm{mg} / \mathrm{ml}$ oil/ethanol solution) used in the topical product which was diluted in Tween 80 for treatment concentrations.

Step 2.3: EGF treatment: The EGF dose (200ng/ml) provided the best detection of phosphorylated-EGFR (p-EGFR) in $1 \%$ media. 
Human EGF (1mg/ml, Gibco \#PHG0211L) was diluted in 1\% FBS/ PBS for treatment concentrations. As shown in figure 2, cells were: 1 ) treated with cetuximab for 1.5 hours at $37^{\circ} \mathrm{C} ; 2$ ) treatment VK1 for 1 hour at $37^{\circ} \mathrm{C}$, and 3 ) treated with EGF for 15 minutes at $37^{\circ} \mathrm{C}$.

Step 2.4: Vehicle Controls: In order to control for vehicles used for VK1 and EGF treatments, similar concentrations of Tween $80(0.3 \mu \mathrm{l}$ or $0.1 \%)$ and $1 \% \mathrm{FBS} / \mathrm{PBS}$ solution $(0.6 \mu \mathrm{l}$ or $0.2 \%)$ were added to each well. Control conditions included untreated, cetuximab alone, VK1 alone, and EGF alone.

Step 3: After incubations, cell lysates were collected using the ELISA Kit Lysis Buffer containing protease and phosphatase inhibitors. P-EGFR and total EGFR were measured using the semiquantitative human phospho-EGFR (y1068) and Total EGFR ELISA kit (RayBiotech, Norcross, GA), following the manufacturer's protocol. Lysates $(100 \mu \mathrm{l})$ were run in duplicate on two separate runs (i.e., each sample was measured four times). Absorbance was read at $450 \mathrm{~nm}$. Absorbance readings were adjusted for background (i.e., blank wells) prior to analyses. The absorbance level represented the level of p-EGFR (i.e., higher absorbance=more $\mathrm{p}$-EGFR). Total EGFR was used as a control to ensure equal amounts of EGFR in each well.

\section{Statistical Analysis}

All statistical analyses were performed using JMP14 Pro at 0.05 level of significance. Univariate Analysis of Variance (ANOVA) was used to examine the differences in and effects on mean concentration of VK1 over time (0 hour, 26 hours, or 50 hours) for each blood sample type (serum $v$ s plasma) and for each skin model (healthy skin $v s$ inflamed skin). Bivariate correlative analyses were used to evaluate the relationship between VK1 concentrations over time. ANOVA was used to examine difference in mean p-EGFR concentrations in A549 cells across various treatment conditions.

\section{Results}

A total of 11 health subjects were enrolled with 10 evaluable. One subject was excluded due to mild (Grade 1) skin irritation upon application of the VK1. The skin irritation was self-limiting and resolved within 24 hours. The majority of evaluable subjects were Caucasian females $(9 / 10$; 90\%) between 22-65 years of age.

\section{Systemic blood concentration of VK1 following topical application}

The extent of systemic plasma and serum concentrations of VK1

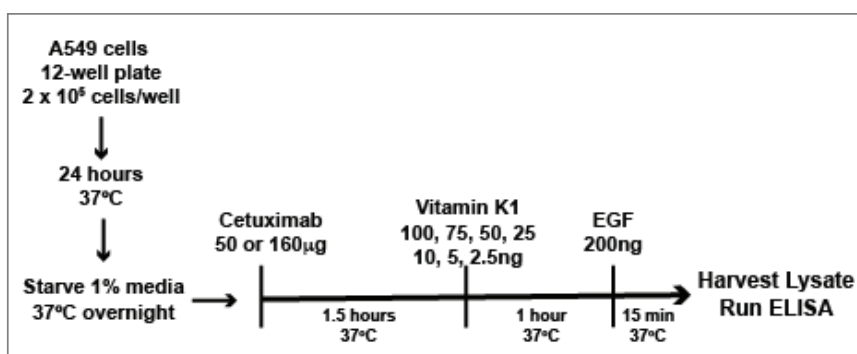

Figure 2: PTreatment of A549 cells with cetuximab, VK1, and EGF. This diagram illustrates the culturing and treatment conditions for the in vitro experiments in A549 cells. Cells were plated at the specified density per well in a 12 -well plate and starved in $1 \%$ media overnight prior to treatment with cetiximab, VK1, and/or EGF. Depending on treatment conditions, cells were treated with cetuximab first for 1.5 hours, followed by VK1 for 1 hour, and then EGF for 15 minutes. from the topical $0.1 \% \mathrm{VK} 1$ application in healthy skin and tape stripped skin of the 9 out of 10 evaluable subjects (Subject 101-110) are shown in figure 3. Subject 110's serum samples were unusable due to hemolysis. VK1 was detectable in all plasma and serum samples, exceptin four serum samples where VK1 levels were not measurable (Figure 3).The concentration of VK1 ranged from 0.067 to $8.22 \mathrm{ng} / \mathrm{ml}$ in plasma and 0 to $4.79 \mathrm{ng} / \mathrm{ml}$ in serum. Application of the topical formulation did not significantly affect the VK1 concentrations in plasma or serum for either healthy or tape stripped skin. This was evident by similar VK1 concentrations at baseline $(0 \mathrm{hr})$ and at two hours following the third (26 hr) and fifth $(50 \mathrm{hr})$ doses of the formulation (Figure 3$)$. Although not statistically significant, mean VK1 levels in serum were higher in tape stripped skin compared to healthy skin (1.14 [0.59,

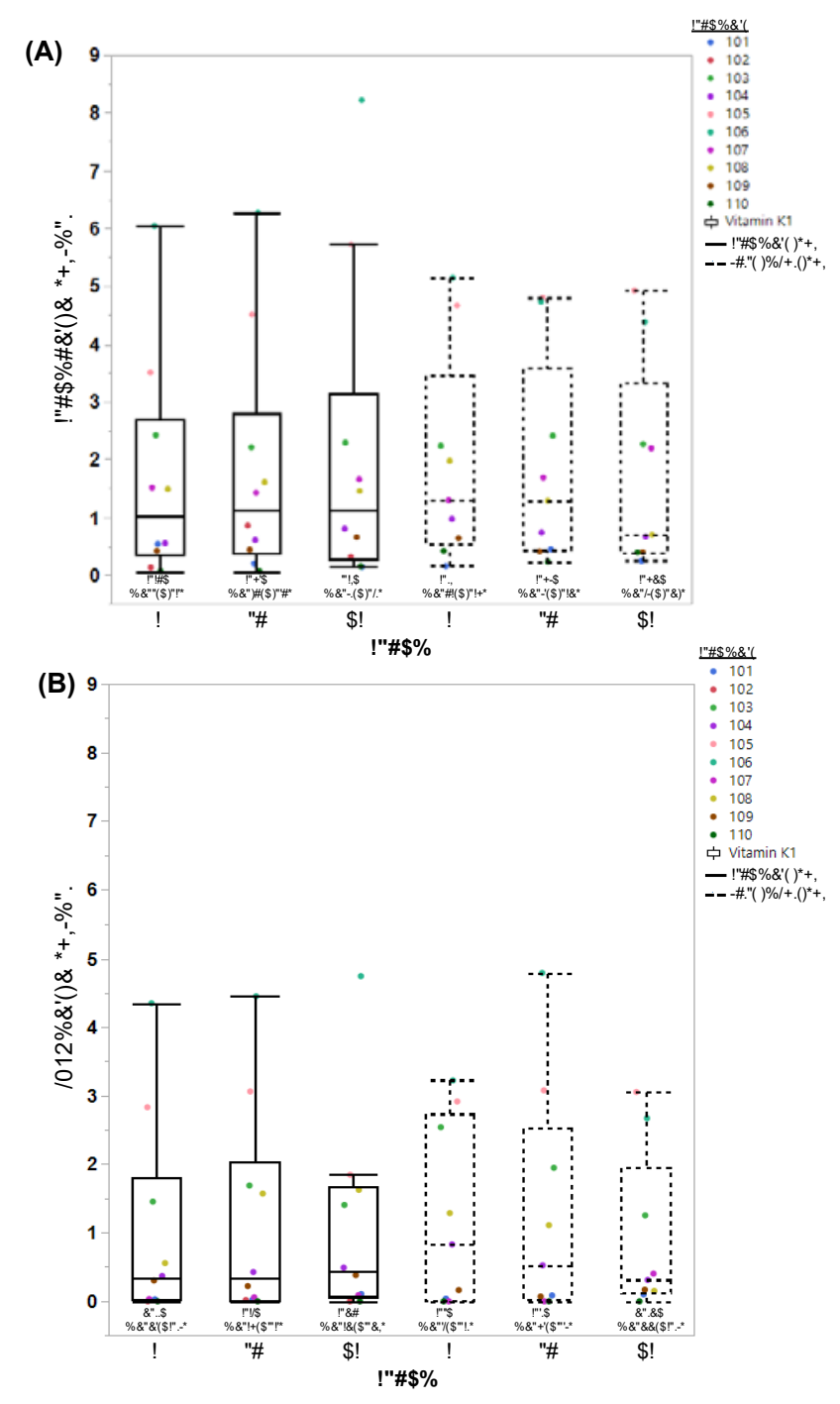

Figure 3: No detectable increase in VK1 blood levels over time. Box plot graphs distribution of mean VK1 levels over time (i.e., hours) in healthy or tape stripped skin in plasma (A) or serum (B). Solid box plots represent values for healthy skin and dashed box plots represent values for tape stripped skin. Each subject is represented by a different colored dot and number as shown in the figure legend. The mean [95\% confidence interval] are shown under each box plot for each time point. 
1.68] vs $1.07[0.53,1.61], \mathrm{p}=0.859)$. However, overall mean plasma VK1 concentrations were significantly greater than mean serum concentrations $(1.87[1.43,2.32] \mathrm{ng} / \mathrm{ml}$ vs $1.10[0.66,1.55] \mathrm{ng} / \mathrm{ml}$, $\mathrm{p}=0.017)$. No change in mean VK1 plasma levels was observed over time in healthy or tape stripped skin ( $\mathrm{p}=0.890$ and $\mathrm{p}=0.985$; Figure 3a). Similar findings were observed in VK1 serum levels over time in healthy skin or tape stripped skin ( $p=0.972$ and $p=0.826$; Figure $3 b$ ). Further, correlative analyses showed no correlation between mean VK1 concentration and time (Pearson $\mathrm{r}=0.008, \mathrm{p}=0.930$ ). Overall, there was minimal systemic VK1 penetration following five topical applications of $0.1 \% \mathrm{VK} 1$ product to healthy or tape stripped skin.

\section{Effect of VK1 on cetuximab-treated A549 cells}

Using a range of VK1 concentrations that encompassed the levels detected in our healthy subjects, we evaluated the ability of VK1 to reverse cetuximab-induced EGFR inhibition in A549 lung cancer cells to ensure the safety of the $0.1 \% \mathrm{VK} 1$ topical product in patients receiving EGFRI therapy. As expected, addition of EGF to A549 cells significantly increased p-EGFR by four-fold and EGF treatment of cetuximab-treated A549 cells resulted in significantly lower p-EGFR levels (Figure 4). EGF alone showed significantly higher levels of p-EGFR than cetuximab-treated cells with or without VK1 (Figure 4). VK1 treatment of cetuximab-treated cells did not significantly increase p-EGFR. These data suggest that VK1 concentrations up to $100 \mathrm{ng} / \mathrm{ml}$ do not reverse cetuximab-induced inhibition of EGFR. These results suggest that this topical $0.1 \%$ VK1 formulation can be used for preliminary evaluations in patients with EGFRI-induced rash.

\section{Discussion}

The EGFRI-induced papulopustular skin reaction negatively impacts patient's quality of life and often results in dose reductions or discontinuation of treatment. A systematic review by Brown J, et al. identified 20 different EGFRI-induced rash management regimens [3]. Overall, Grade 1 rashes are treated with topical antibiotics or corticosteroids, Grade 2 rashes are treated with oral antibiotics and antihistamines, and Grade 3 or higher rashes are mitigated with

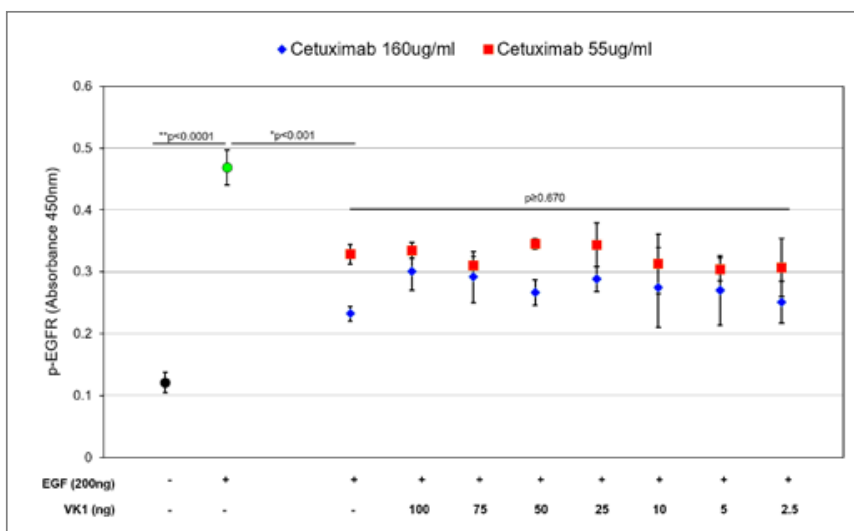

Figure 4: VK1 did not increase p-EGFR in cetuximab-treated A549 cells.

A549 cells were treated with $(+)$ or without $(-)$ cetuximab $(55 \mathrm{mg} /$ $\mathrm{ml}$ or $160 \mathrm{mg} / \mathrm{ml}$ ), VK1 (2.5 to $100 \mathrm{ng} / \mathrm{ml})$, and EGF $(200 \mathrm{ng} / \mathrm{ml})$. Levels $p$-EGFR are shown for each condition as "mean +/- SD. Black circle=untreated; Green circle=EGF only; Red square $=55 \mu \mathrm{g}$ cetuximab; Blue diamond $=160 \mu$ g cetuximab. EGF only vs untreated: $* * p<0.0001$. Cetuximab/EGF vs EGF only: ${ }^{*} p<0.001$. VK1-treated vs Cetuximab/ EGF: $p \geq 0.670$. oral corticosteroids, dose reductions, and treatment delays [3]. Although, there is questionable clinical evidence supporting the use of corticosteroids, they are often used as standard care for rash management. A recently published study reported the potential for a doxycycline foam to prevent the onset of the EGFRI rash; however, a larger confirmatory study is required [31]. Better interventions for EGFRI-induced rash management are necessary in order to improve patient's quality of life and treatment effectiveness.

Topical VK1, a phosphatase inhibitor, has been identified as a potential therapeutic option for EGFRI-induced rash due to its ability to abrogate EGFR inhibition by reversing activated EGFR dephosphorylation and favouring re-activation of EGFR signalling in the skin [19]. However, the need to avoid this activity systemically is critical because of the potential to reverse the anti-cancer activity of the EGFRIs. In 2013, Tomkova H, et al. showed that pre-treatment with VK1 cream before EGFRI infusion did not prevent the onset of the rash [24]. In 2018, Hofheinz RD, et al. showed that topical VK1 combined with doxycycline reduced rash severity by WoMo criteria, but not percentage of affected skin surface, in the EVITA trial [23]. In a post-hoc analysis of the EVITA trial, Gaiser MR, et al. showed that the topical VK1 cream reduced the incidence and severity of cetuximab-induced rash in women [22]. While the clinical efficacy data are encouraging, none of these studies conducted safety measures to ensure the absence of systemic penetration. Because the topical VK1 (Reconval ${ }^{\circ} \mathrm{K} 1$ ) used in these studies is not available in the United States, our group formulated multiple topical VK1 products with varying absorption rates in porcine skin [25]. The current study selected the formulation with the most optimal skin penetration based on in vitro Franz diffusion cell model evaluations. Our results showed that the systemic levels from topical application of the selected $0.1 \%$ VK1 product did not interfere with cetuximab inhibition of EGFR in A549 lung cancer cells. We tested VK1 concentrations ten times higher than the highest detectable VK1 plasma level (i.e., $8.22 \mathrm{ng} /$ $\mathrm{ml}$ ) to ensure that systemic VK1 would not interfere with cetuximab inhibition of EGFR.

Tape stripping is a common technique used in dermatologic research to evaluate skin barrier function and penetration of topically applied drugs $[28,29]$. Tape stripping is known to disrupt the skin barrier and increase inflammation. This model was used to simulate inflamed areas of EGFRI-induced rash in patients. To best simulate the skin barrier disruption from EGFRI therapy, we used ten tape strips prior to each topical application (i.e., every 12 hours). The repeated tape stripping every 12 hours prevented full recovery of the skin barrier, which usually takes 24 hours [27,32], creating a chronically impaired skin barrier. Further, Chandra F, et al. showed that EGFRI therapy causes increased transepidermal water loss (TEWL) of $11.5 \mathrm{~g} /$ $\mathrm{m}^{2} \mathrm{~h}$ [33]. Although we did not measure TEWL in this study, ten tape strips have been shown to result in similar TEWL levels (e.g., $9.1 \mathrm{~g} / \mathrm{m}^{2} \mathrm{~h}$ ) [34]. Additionally, forearm skin is thinner than face skin $(1.26-1.3 \mathrm{~mm}$ vs $1.5-1.7 \mathrm{~mm}$ ), suggesting our methods produced barrier disruption similar to EGFRI therapy. We did not observe greater VK1 penetration in tape stripped skin demonstrating minimal systemic penetration from this VK1 formulation even with removal of stratum corneum. A limitation of this preliminary study is the $2 \%$ body surface area (BSA) to which the topical VK1 was applied compared to the pastulopustular rash which can cover over 30\% BSA [3]. Assuming the drug follows linear pharmacokinetics, one can expect the plasma concentration to increase by a factor of $30 / 2$ or 15 fold if $30 \%$ BSA were treated. Therefore, if the mean concentration in this study measured at $1.87 \mathrm{ng} /$ $\mathrm{mL}$ with $2 \%$ BSA application, the predicted concentration would be $28 \mathrm{ng} / \mathrm{mL}(1.87 \times 15)$ for a $30 \%$ BSA application with an upper $95 \%$ 
confidence limit of $35 \mathrm{ng} / \mathrm{ml}(2.32 \times 15)$. As discussed above, our in vitro A549 lung cancer cell study showed thatVK1 at $100 \mathrm{ng} / \mathrm{ml}$ did not reverse cetuximab inhibition of EGFR (Figure 4). Even if the maximum concentration of $8.22 \mathrm{ng} / \mathrm{ml}$ was used to predict plasma concentration for a $30 \%$ BSA application, the predicted concentration would be $123 \mathrm{ng} / \mathrm{ml}$. However, all subjects, except one subject, had VK1 plasma levels lower than $6.0 \mathrm{ng} / \mathrm{ml}$, which would estimate a $90 \mathrm{ng} / \mathrm{ml}$ VK1 plasma concentration for a $30 \%$ BSA application. These predicted concentrations are most likely an overestimation of the actual concentrations because major portions of the measured VK1 concentrations after the topical application belonged to the endogenous VK1 present in the pre-treatment samples (Figure 3). Indeed, no significant differences were observed between the plasma or serum VK1 concentrations in samples before and after treatment with our formulation (Figure 3). Nevertheless, future pharmacokinetic studies in a patient cohort with EGFRI-induced rash would provide critical information regarding the systemic VK1 absorption following application of our formulation with increased BSA percentages. Based on our results, our $0.1 \%$ topical VK1 product appears safe for further pharmacokinetic studies in patients with low grade EGFRIinduced rash.

The majority of healthy subjects in our pharmacokinetic safety study showed normal range of VK1 levels in plasma and serum (0.1-4.2ng/ $\mathrm{ml}$ ) following topical application to healthy or inflamed skin [35]. Two subjects (Subjects 105 and 106) showed elevated VK1 levels at baseline (i.e.>4.2ng.ml), which could be a reflection of their diet or unknown medical abnormality. Subjects were not required to abstain from VK1containing food (i.e., dark green leafy vegetables) or maintain a food diary. Based on our in vitro assays, these increased levels of VK1 would not interfere with EGFRI (i.e., cetuximab) therapy.

Another limitation in the study was the lack of effect observed with VK1 in A549 cells. We expected VK1 to increase p-EGFR in cetuximab-treated A549 cells; however, we were unable to identify aVK1 concentration that reversed cetuximab inhibition of EGFR. Most likely, a much higher VK1 concentration (i.e., >100ng/ml) is necessary to increase p-EGFR. In 2011, Perez-Soler R, et al. published that vitamin K3 (i.e., menadione) increased baseline EGFR phosphorylation through phosphatase inhibition; however this paper was later retracted [19]. Therefore, it remains unclear if VK1 would phosphorylate EGFR or what VK1 dose is required for this effect. Other publications report anti-inflammatory effects of VK1 in skin without description of a direct mechanism [20,36,37]. Furthermore, intake of 250mg of VK1 did not interfere with war far in, suggesting systemic drug interference requires high VK1 levels [38]. Additional research is required for better understanding of the mechanistic effects of VK1 in skin.

Overall, our results suggest that our $0.1 \%$ topical VK1cream has minimal systemic penetration and is expected to be safe for use in patients receiving EGFRI therapy. The amount of VK1 systemically absorbed through topical application did not interfere with cetuximabinhibition in A549 cells. Systemic VK1 levels up to $100 \mathrm{ng} / \mathrm{ml}$ would not interfere with EGFRI therapy. Our next step will be to test the effectiveness of our $0.1 \%$ topical VK1 formulation for EGFRI-induced rash in patients receiving EGFRI in a randomized, placebo-controlled, blinded study.

\section{Acknowledgements}

This study was supported by the SWOG Hope Foundation SEED Grant \#500313-0001 and Chapman University Faculty Pilot Award. We thank all healthy volunteers for their participation in this study;
Dr. Jacob Finkelstein at the University of Rochester for providing the A549 lung cancer cells; and the Investigational Drug Pharmacy at the University of Rochester for providing the cetuximab.

\section{References}

1. Nyati MK, Morgan MA, Feng FY, Lawrence TS (2006) Integration of EGFR inhibitors with radiochemotherapy. Nat Rev Cancer 6: 876885.

2. Robert C, Soria JC, Spatz A, Le Cesne A, Malka D, et al. (2005) Cutaneous side-effects of kinase inhibitors and blocking antibodies. Lancet Oncol 6: 491-500.

3. Brown J, Su Y, Nelleson D, Shankar P, Mayo C (2016) Management of epidermal growth factor receptor inhibitor-associated rash: a systematic review. J Community Support Oncol 14: 21-28.

4. Chanprapaph K, Vachiramon V, Rattanakaemakorn P (2014) Epidermal growth factor receptor inhibitors: a review of cutaneous adverse events and management. Dermatol Res Pract 2014: 734249.

5. Lacouture ME, Anadkat MJ, Bensadoun RJ, Bryce J, Chan A, et al. (2011) Clinical practice guidelines for the prevention and treatment of EGFR inhibitor-associated dermatologic toxicities. Support Care Cancer 19: 1079-1095.

6. Wagner LI, Lacouture ME (2007) Dermatologic toxicities associated with EGFR inhibitors: the clinical psychologist's perspective. Impact on health-related quality of life and implications for clinical management of psychological sequelae. Oncol 21: 34-36.

7. Cunningham $D$, Humblet $Y$, Siena $S$, Khayat $D$, Bleiberg $H$, et al. (2004) Cetuximab monotherapy and cetuximab plus irinotecan in irinotecan-refractory metastatic colorectal cancer. N Engl J Med 351: 337-345.

8. Perez-Soler R, Delord JP, Halpern A, Kelly K, Krueger J, et al. (2005) HER1/EGFR inhibitor-associated rash: future directions for management and investigation outcomes from the HER1/EGFR inhibitor rash management forum. Oncologist 10: 345-356.

9. Perez-Soler R, Saltz L (2005) Cutaneous adverse effects with HER1/ EGFR-targeted agents: is there a silver lining? J Clin Oncol 23: 52355246.

10. Gerber PA, Meller S, Eames T, Buhren BA, Schrumpf H, et al. (2012) Management of EGFR-inhibitor associated rash: a retrospective study in 49 patients. Eur J Med Res 17: 4.

11. Li T, Perez-Soler R (2009) Skin toxicities associated with epidermal growth factor receptor inhibitors. Targeted Oncol 4: 107-119.

12. Melosky B, Leighl NB, Rothenstein J, Sangha R, Stewart D, et al. (2015) Management of egfr tki-induced dermatologic adverse events. Curr Oncol 22: 123-132.

13. Mittmann N, Seung SJ (2011) Rash rates with egfr inhibitors: metaanalysis. Curr Oncol 18: e54-e63.

14. Petrelli F, Borgonovo K, Barni S (2016) Preventing or treating antiEGFR related skin rash with antibiotics? Ann Transl Med 4: 312.

15. Ocvirk J (2010) Management of cetuximab-induced skin toxicity with the prophylactic use of topical vitamin K1 cream. Radiol Oncol 44: 265-266.

16. Ocvirk J, Heeger S, McCloud P, Hofheinz RD (2013) A review of the treatment options for skin rash induced by EGFR-targeted therapies: Evidence from randomized clinical trials and a meta-analysis. Radiol Oncol 47: 166-175. 
17. Pinto C, Ferrari D, Di Tullio P, Latiano TP, Orlandi A, et al. (2001) Topical vitamin $\mathrm{K} 1$ in the management of skin rash during antiEGFR monoclonal antibody treatment in patient with metastatic cancer: Italian Observational Study. Journal of Clinical Oncology 29(supplement): Abstract 594.

18. Barton-Burke M, Ciccolini K, Mekas M, Burke S (2017) Dermatologic Reactions to Targeted Therapy: A Focus on Epidermal Growth Factor Receptor Inhibitors and Nursing Care. Nurs Clin North Am 52: 83113.

19. Perez-Soler R, Zou Y, Li T, Ling YH (2011) The phosphatase inhibitor menadione (vitamin K3) protects cells from EGFR inhibition by erlotinib and cetuximab. Clin Cancer Res 17: 6766-6777.

20. Holcmann M, Sibilia M (2015) Mechanisms underlying skin disorders induced by EGFR inhibitors. Mol Cell Oncol 2: e1004969.

21. Newswire G (2008) Hana Biosciences Completes Phase 1 Clinical Trial of Menadione, Its Novel First-in-class Compound for TreatmentLimiting Skin Toxicity Associated with EGFR Inhibitors. Talon Therapeutics.

22. Gaiser MR, Lorenzen S, Merx K, Trojan J, Ocvirk J, et al. (2018) Vitamin $\mathrm{K} 1$ cream significantly reduces incidence and severity of cetuximabrelated acneiform skin rash in women: a post hoc analysis of the EVITA trial. Ann Oncol 29: 2393-2395.

23. Hofheinz RD, Lorenzen S, Trojan J, Ocvirk J, Ettrich TJ, et al. (2018) EVITA-a double-blind, vehicle-controlled, randomized phase II trial of vitamin K1 cream as prophylaxis for cetuximab-induced skin toxicity. Ann Oncol 29: 1010-1015.

24. Tomkova H, Pospiskova $M$, Zabojnikova $M$, Kohoutek $M$, Serclova $M$, et al. (2013) Phytomenadione pre-treatment in EGFR inhibitorinduced folliculitis. J Eur Acad Dermatol Venereol 27: 514-519.

25. Nabiee R, Dubois B, Green L, Sharma A, Wong SF, et al. (2018) In vitro and ex-vivo evaluation of topical formulations designed to minimize transdermal absorption of Vitamin K1. PLoS One 13: e0204531.

26. Jacobi U, Weigmann HJ, Ulrich J, Sterry W, Lademann J (2005) Estimation of the relative stratum corneum amount removed by tape stripping. Skin Res Technol 11: 91-96.

27. von Moos S, Johansen P, Tay F, Graf N, Kundig TM, et al. (2014) Comparing safety of abrasion and tape-stripping as skin preparation in allergen-specific epicutaneous immunotherapy. J Allergy Clin Immunol 134: 965-967.e4.
28. Gee CM, Nicolazzo JA, Watkinson AC, Finnin BC (2012) Assessment of the lateral diffusion and penetration of topically applied drugs in humans using a novel concentric tape stripping design. Pharm Res 29: 2035-2046.

29. Olesen CM, Fuchs CSK, Philipsen PA, Haedersdal M, Agner T, et al. (2019) Advancement through epidermis using tape stripping technique and Reflectance Confocal Microscopy. Sci Rep 9: 12217.

30. Tan AR, Moore DF, Hidalgo M, Doroshow JH, Poplin EA, et al. (2006) Pharmacokinetics of cetuximab after administration of escalating single dosing and weekly fixed dosing in patients with solid tumors. Clin Cancer Res 12: 6517-6522.

31. Shacham Shmueli E, Geva R, Yarom N, Hubert A, Keynan R, et al (2019) Topical doxycycline foam $4 \%$ for prophylactic management of epidermal growth factor receptor inhibitor skin toxicity: an exploratory phase 2, randomized, double-blind clinical study. Supportive Care Cancer 27: 3027-3033.

32. Muizzuddin N, Matsui MS, Marenus KD, Maes DH (2003) Impact of stress of marital dissolution on skin barrier recovery: tape stripping and measurement of trans-epidermal water loss (TEWL). Skin Res Technol 9: 34-38.

33. Chandra F, Sandiono D, Sugiri U, Suwarsa O, Gunawan H (2017) Cutaneous Side Effects and Transepidermal Water Loss To Gefitinib: A Study of 11 Patients. Dermatol Ther (Heidelb) 7: 133-141.

34. Osman-Ponchet $\mathrm{H}$, Gaborit A, Kouidhi M, Anglars S, Marceau-Suissa J, et al. (2017) Comparison of the Effect of Skin Preparation Pads on Transepidermal Water Loss in ex vivo Human Skin. Dermatol Ther (Heidelb) 7: 407-415.

35. Kraemer CM (2015) Viatmin K. Medscape.

36. Hemmati AA, Houshmand G, Ghorbanzadeh B, Nemati M Behmanesh MA (2014) Topical vitamin K1 promotes repair of full thickness wound in rat. Indian J Pharmacol 46: 409-412.

37. Shin JU, Park JH, Cho BC, Lee JH (2012) Treatment of epidermal growth factor receptor inhibitor-induced acneiform eruption with topical recombinant human epidermal growth factor. Dermatology 225: 135-140.

38. Lurie Y, Loebstein R, Kurnik D, Almog S, Halkin H (2010) Warfarin and vitamin $\mathrm{K}$ intake in the era of pharmacogenetics. Br J Clin Pharmacol 70: $164-170$. 